\title{
The effects of fasting on the thermogenic, metabolic and cardiovascular responses to infused adrenaline
}

\author{
BY J. WEBBER ${ }^{1}$, J. TAYLOR ${ }^{1}$, H. GREATHEAD ${ }^{2}$, J. DAWSON ${ }^{2}$, P. J. BUTTERY ${ }^{2}$ \\ AND I. A. MACDONALD ${ }^{1 *}$ \\ ${ }^{1}$ Department of Physiology and Pharmacology, Medical School, Queen's Medical Centre, \\ Nottingham NG7 $2 U H$ \\ ${ }^{2}$ Faculty of Agricultural and Food Sciences, Sutton Bonington Campus, Loughborough, \\ University of Nottingham, Leicestershire LE12 5RD
}

(Received 10 November 1994 - Revised 26 January 1995 - Accepted 3 February 1995)

\begin{abstract}
The effects of fasting on the thermogenic, lipolytic and cardiovascular responses to adrenaline were examined in nine normal, young, non-obese subjects. Each subject attended for study after 12, 36 and $72 \mathrm{~h}$ fasting. After basal measurements adrenaline was infused at $25 \mathrm{ng} / \mathrm{min}$ per $\mathrm{kg}$ ideal body weight for $90 \mathrm{~min}$. Fasting increased the thermogenic effect of the adrenaline (mean 14.6 (SE 1.7), 16.6 (SE 1.8), 22.6 (SE 1.6) $\mathrm{J} / \mathrm{min}$ per $\mathrm{kg}$ fat-free mass after 12,36 and $72 \mathrm{~h}$ fasting respectively; $P<0.001$, ANOVA). Basal plasma palmitate turnover increased with duration of fasting (1.48 (SE 0.22), 1.95 (SE 0.34) and 2.26 (SE 0.33) $\mu \mathrm{mol} / \mathrm{min}$ per $\mathrm{kg}$ body weight; $P<0.001$, ANOVA), but the response to adrenaline was unaffected by fasting. The percentage values for basal plasma palmitate turnover oxidized were 44 (SE 2 ; $12 \mathrm{~h}$ ), 46 (SE 5; $36 \mathrm{~h}$ ) and 42 (SE 4)\% (72 h). In response to adrenaline this percentage fell, suggesting that adrenaline infusion may favour intra-tissue lipid oxidation.
\end{abstract}

Sympathetic nervous system: Metabolic rate: Heart rate: Lipolysis: $\left[1-{ }^{13}\right.$ C]palmitate

The fasting state is characterized by a number of changes in energy metabolism and substrate utilization. These changes include a reduction in resting energy expenditure and the predominant use of fat as a fuel source. The sympathoadrenal system is felt to have a major role to play in the regulation of these changes. In animal studies noradrenaline turnover (an index of sympathetic nervous system (SNS) activity) is reduced during fasting in a number of tissues (Landsberg \& Young, 1978), whilst refeeding reverses these changes. Studies which have examined whole-body noradrenaline turnover in healthy human volunteers have shown increases in turnover during overfeeding and the reverse of these changes during undernutrition (O'Dea et al. 1982).

Despite the well-documented decrease in resting metabolic rate (RMR) with fasting, it has been shown recently that short fasts (less than $72 \mathrm{~h}$ ) are associated with an elevated RMR (Mansell et al. 1990; Webber \& Macdonald, 1994). The reasons for this are not completely clear, but may be related to the energy costs of gluconeogenesis and ketogenesis. The elevation in RMR is still somewhat paradoxical when the documented decreases in sympathetic activity after short periods of underfeeding are considered (O'Dea et al. 1982). However, changes in indices of sympathetic activity may not accurately reflect the overall physiological effect of changed nutritional status. Alterations in adrenoceptor number and/or sensitivity and in post-receptor events may modulate the effects of changes in sympathetic activity.

Exogenous infusions of catecholamines may be used to assess receptor sensitivity. When

* For reprints. 
adrenaline is infused into healthy young subjects who have been fasting for $48 \mathrm{~h}$, the thermogenic and heart-rate responses are significantly enhanced compared with the control $12 \mathrm{~h}$ fasted state (Mansell et al. 1990). Likewise, the lipolytic response to adrenaline has been shown to be greater after an $84 \mathrm{~h}$ fast, independent of the fall in plasma insulin which occurs with fasting (Jensen et al. 1987). The importance of adrenergic mechanisms in facilitating fat mobilization during fasting is further emphasized by the demonstration that $\beta$-blockade has a greater antilipolytic effect after $84 \mathrm{~h}$ fasting than after $12 \mathrm{~h}$ (Klein et al. 1989).

The current study was designed to examine the time course of the changes induced by fasting in a number of adrenoreceptor-mediated processes, namely, cardiovascular, metabolic and thermogenic responses to adrenaline infusions, and to use stable-isotope methodology to look at fatty acid turnover and oxidation in more detail. In particular it was designed to document how fasting and adrenaline affect the relationships between turnover and oxidation of fatty acids and between plasma and tissue fatty acid oxidation. Baseline data for the subjects in this study form part of the results previously reported for twenty-nine fasting subjects (Webber \& Macdonald, 1994).

\section{METHODS}

Nine healthy, non-obese subjects (four men, five women) were recruited (mean age 22.9 (SE 1.2) years; weight 64.2 (SE 4.2) kg, height 1.70 (SE 0.03) m, and BMI 22.0 (SE 0.80$) \mathrm{kg} / \mathrm{m}^{2}$ ). Mean fat-free mass (estimated from skinfold thickness measurements after the $12 \mathrm{~h}$ fast; Durnin \& Womersley, 1974) was 50.2 (SE 3.2) kg. None was taking any medication other than the oral contraceptive pill. All gave written informed consent to the study which was approved by the University of Nottingham Medical School Research Ethics Committee.

The subjects were each studied on three occasions, after either a 12,36 , or $72 \mathrm{~h}$ fast, the $12 \mathrm{~h}$ (overnight) fast being taken as the post-absorptive control period against which the values at 36 and $72 \mathrm{~h}$ were compared. The studies were done in random order and there was a gap of at least $7 \mathrm{~d}$ normal food intake between each fasting period. All the women were studied during the follicular phase of the menstrual cycle (Webb, 1986). During the fasting period subjects were allowed water ad lib., proprietary flavoured carbonated drinks (One Cal, RHM Foods, Hartlepool, Cleveland) and black decaffeinated tea and coffee without sugar. Whilst fasting, subjects consumed $80 \mathrm{mmol} \mathrm{Na}$ and $50 \mathrm{mmol} \mathrm{K}$ daily as slow-release tablets to minimize the potentially confounding effects of fluid deprivation and intravascular volume depletion on SNS activity and cardiovascular reflexes.

Studies took place in a temperature-controlled room $\left(28^{\circ}\right)$ with the subjects wearing a Tshirt and shorts only. On arrival the subjects voided to provide a timed collection of urine. They then rested supine whilst intravenous cannulas were inserted under local anaesthetic, and the monitoring equipment was attached. For blood sampling, a $44 \mathrm{~mm}, 20$ gauge catheter (Jelco, Criticon Inc, Tampa, FL, USA) was inserted retrogradely into a vein on the dorsum of the hand and kept patent with a slow running infusion of saline $(154 \mathrm{mmol}$ $\mathrm{NaCl} / 1)$. This hand rested in a warm air box $\left(55-60^{\circ}\right)$ to obtain 'arterialized' venous blood samples (McGuire et al. 1976). Blood samples were withdrawn via a three-way tap with the first $2 \mathrm{ml}$ being discarded to avoid contamination with saline. A second cannula was placed in an ipsilateral antecubital vein for infusions of $\left[1,{ }^{13} \mathrm{C}\right]$ palmitate and adrenaline.

Continuous recordings of $\mathrm{O}_{2}$ consumption and $\mathrm{CO}_{2}$ production were made using a ventilated-canopy indirect calorimeter (Fellows \& Macdonald, 1985). Heart rate (HR) was recorded from an electrocardiogram, and brachial arterial blood pressure was measured using an automated sphygmomanometer (Accutorr 1A, Datascope Corporation, Paramus, NJ, USA). Right forearm blood flow (FBF) was determined by venous occlusion 
plethysmography using a mercury-in-rubber strain gauge (Whitney, 1953), with an arterial occlusion cuff at the wrist.

Three blood samples were taken for measurement of the background enrichment of plasma $\left[1,{ }^{13} \mathrm{C}\right]$ palmitate and three samples of expired air were collected into evacuated glass tubes for measurement of background ${ }^{13} \mathrm{CO}_{2}$ enrichment. A priming dose of $1.3 \mu \mathrm{mol}$ $\mathrm{NaH}^{13} \mathrm{CO}_{3} / \mathrm{kg}(9 \%$ atom percent excess (APE), Cambridge Isotopes, MA, USA) was then given (Allsop et al. 1978) followed by a continuous infusion of $\mathrm{K}\left[1,{ }^{13} \mathrm{C}\right]$ palmitate $(99 \%$ APE, Cambridge Isotopes) at approximately $0.04 \mu \mathrm{mol} / \mathrm{min}$ per $\mathrm{kg}$ ideal body weight for the duration of the study. The exact infusion rate of $\left[1,{ }^{13} \mathrm{C}\right]$ palmitate was calculated by measuring the concentration of isotope in the infusate and multiplying the value by the infusion rate. The palmitate solution was prepared by the addition of $K\left[1,{ }^{13} \mathrm{C}\right]$ palmitate to $5 \mathrm{ml}$ sterile water at $60^{\circ}$. The resulting mixture was passed through a millipore filter $(0.22 \mu \mathrm{m})$ into a preheated $\left(60^{\circ}\right)$ bottle of human albumin solution (Bio Products Laboratory, Elstree, Herts). Each infusate was analysed for palmitate concentration and isotopic enrichment as described below.

Measurements of gas exchange, HR, blood pressure and FBF were made from 20 min into the $\left[1,{ }^{13} \mathrm{C}\right]$ palmitate infusion onwards. Between 45 and $60 \mathrm{~min}$ into the infusion, four arterialized venous blood samples were taken at intervals of $5 \mathrm{~min}$ for later measurement of plasma $\left[1,{ }^{13} \mathrm{C}\right]$ palmitate APE, and four expired-air samples were obtained for measurement of ${ }^{13} \mathrm{CO}_{2}$ enrichment. During this period blood was also taken for later analysis of glucose, lactate, glycerol, 3-hydroxybutyrate, plasma non-esterified fatty acids (NEFA), insulin, noradrenaline, adrenaline and urea. An adrenaline infusion was commenced after $60 \mathrm{~min}$, at a rate of $25 \mathrm{ng} / \mathrm{min}$ per $\mathrm{kg}$ ideal body weight, and continued for a further $90 \mathrm{~min}$. Throughout the period of adrenaline infusion continuous measurements of $\mathrm{O}_{2}$ consumption and $\mathrm{CO}_{2}$ production were made. Blood samples were obtained and cardiovascular measurements were made at intervals of $10 \mathrm{~min}$ during the adrenaline infusion. On completion of the study subjects provided a further urine sample.

The adrenaline infusates (adrenaline BP, Martindale Pharmaceuticals, Romford, Essex) were prepared as $3 \mu \mathrm{g} / \mathrm{ml}$ solutions in saline with $1 \mathrm{mg} / \mathrm{ml}$ abscorbic acid added as a preservative. The exact concentration of the infusates was measured using HPLC with electrochemical detection (Macdonald \& Lake, 1985). A Vickers Treonic IP4 pump (Vickers Limited, Basingstoke, Hants) was used to infuse the adrenaline at a rate of $25 \mathrm{ng} / \mathrm{min}$ per $\mathrm{kg}$ body weight.

\section{Analyses}

Plasma palmitate was extracted following the method of Hachey et al. (1991), with the exception that iodomethane was used instead of $\alpha$-bromo-2,3,4,5,6-pentafluorotoluene. Heptadecanoic acid was used as an internal standard and was made up in hexane and dried under $\mathrm{N}_{2}$. Plasma ( $\left.250 \mu \mathrm{l}\right)$ was added to the internal standard followed by $250 \mu \mathrm{l} 0.01 \mathrm{M}$ tetrabutylammonium hydrogen sulphate solution and $250 \mu \mathrm{l} 0.13 \mathrm{M}$-iodomethane solution. The mixtures were then vortexed for $2 \mathrm{~min}$ followed by $1 \mathrm{~h}$ sonication. They were then placed in a refrigerator $\left(4^{\circ}\right)$ overnight. Ethanol $(1 \mathrm{ml} ; 100 \mathrm{ml} / 1$ in hexane $)$ and $1 \mathrm{ml}$ saturated $\mathrm{NaCl}$ were then added and the mixture was vortexed for $45 \mathrm{~s}$ and centrifuged at $3000 \mathrm{rev} / \mathrm{min}$ for $10 \mathrm{~min}$. The upper, organic phase was transferred to a GC vial and dried under $\mathrm{N}_{2}$. The derived esters were redissolved in $1 \mathrm{ml}$ hexane, the vials were capped and stored at $-20^{\circ}$ for later analysis. The same procedure was followed when the palmitate standards for calibration were used. An HP 5890 II gas chromatograph and an HP 5970 mass selective detector were used for the measurements of plasma palmitate concentration and ${ }^{13} \mathrm{C}$ enrichment by electron impact and selective ion monitoring of ions $\mathrm{m} / \mathrm{z} 270 / 271$ (Hewlett Packard, Scientific Instruments Division, Palo Alto, CA, USA). 
For the studies of fatty acid oxidation an end-expiratory gas sample was obtained using a Douglas bag, and was subsequently transferred into evacuated glass tubes (Exetainer; Labco Ltd, High Wycombe, Bucks). A Europa Scientific Tracer Mass Stable Isotope Analyser (Europa House, Crewe, Ches.) was used to measure expired-air ${ }^{13} \mathrm{CO}_{2}$ enrichment.

Blood glucose was measured using a Yellow Springs analyser (YSI 23 AM; Yellow Springs Industries, $\mathrm{OH}$, USA). For measurements of lactate, glycerol and 3hydroxybutyrate, $1 \mathrm{ml}$ blood was deproteinized in a preweighed tube containing $0.1 \mathrm{M}-$ perchloric acid, the tube was then reweighed and the supernatant fraction stored at $-20^{\circ}$ for later analysis (Lloyd et al. 1978). Total NEFA were measured in plasma (Knox \& Jones, 1984).

For the measurement of plasma catecholamines, $2 \mathrm{ml}$ plasma was mixed with $75 \mu \mathrm{l}$ EGTA glutathione (antioxidant) and stored at $-80^{\circ}$ for subsequent determination of adrenaline and noradrenaline concentrations using HPLC with electrochemical detection (Macdonald \& Lake, 1985).

Insulin was measured using a commercial double antibody method (Coat-a-Count; DPL Division, Euro/DPC Limited, Los Angeles, CA, USA). Free thyroxine and free triiodothyronine were measured with kits (Amerlex M; Kodak Clinical Diagnostics Limited, Amersham, Bucks.).

Urinary $\mathrm{N}$ concentrations were measured by the method of Kjeldahl. Using these values and those for blood urea, corrected urinary $\mathbf{N}$ excretion rates and hence protein oxidation rates were calculated (Jequier et al. 1987).

From the respiratory exchange data, calculations of metabolic rate (Weir, 1949) and respiratory exchange ratio (RER) were made. Substrate oxidation rates were calculated from these values and those obtained for protein oxidation (Jequier et al. 1987), using the values for the energy equivalents of protein, fat and carbohydrate derived by Livesey \& Elia (1988). Thus, for fat $19.6 \mathrm{~kJ}$ is the energy equivalent per litre $\mathrm{O}_{2}$ consumed and the energy content of the fat is $39.5 \mathrm{~kJ} / \mathrm{g}$.

Steady-state equations were used for the calculation of turnover rates of palmitate both in the basal state and in response to the adrenaline infusion. It appears that when fatty acid turnover rates are increasing, steady-state equations can be used without loss of accuracy, because of the rapid turnover of circulating fatty acids (Jensen et al. 1990), whilst the use of non-steady-state equations requires the choice of an optimal effective volume of distribution. Palmitate oxidation was calculated using the equations of Wolfe et al. (1980), using 0.76 as the correction factor to allow for the fact that not all the ${ }^{13} \mathrm{CO}_{2}$ produced at the cellular level is excreted in the breath (Wenham et al. 1991).

All data are reported as means with their standard errors in parentheses. Statistical analysis of the results was performed by two-way ANOVA with repeated measures using the statistical package BMDP (BMDP, Los Angeles, CA, USA). Initially changes in variables caused by fasting alone were compared by ANOVA, and then the effects of adrenaline on these variables after the three periods of fasting were analysed. Where ANOVA indicated a significant treatment-time effect the exact level of significance at each time point was calculated using a paired $t$ test. A Bonferroni correction was used for multiple paired comparisons.

\section{RESULTS}

\section{Basal thyroid function and plasma insulin}

Free triiodothyronine fell progressively from 5.3 (SE 0.2 ) to 4.6 (SE 0.2 ) to 3.5 (SE 0.3 ) pmol/1 $(P<0.001$, ANOVA) after 12,36 and $72 \mathrm{~h}$ fasting respectively. There was no change in free thyroxine over this period (12.8 (SE 0.7), 13.3 (SE 0.9) and 13.1 (SE 0.8) pmol/1 respectively). 

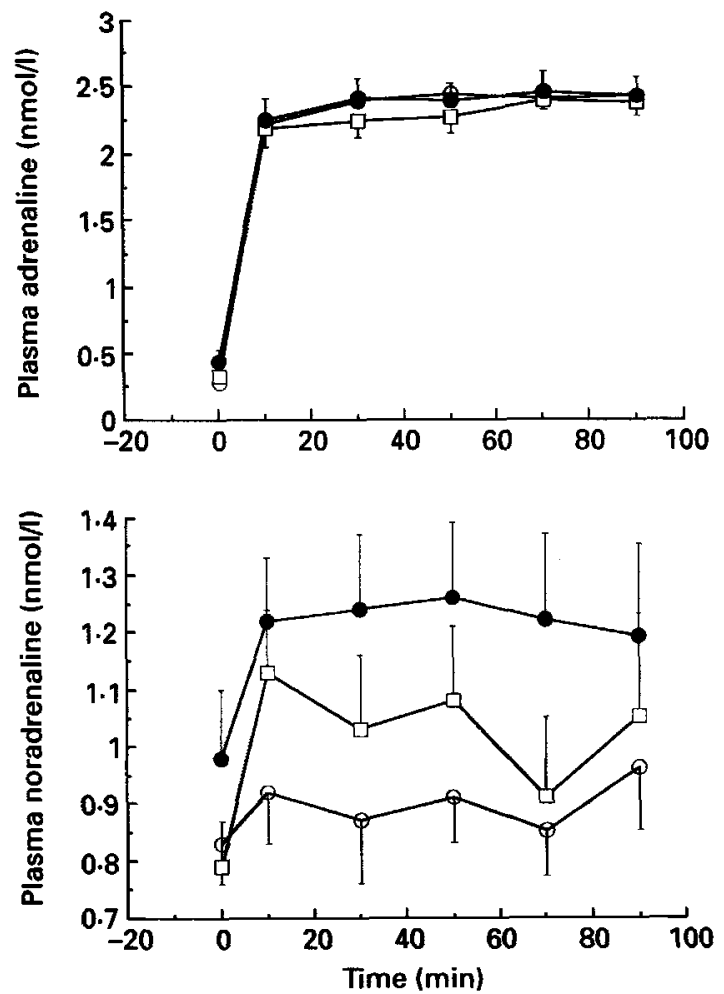

Fig. 1. Plasma adrenaline and noradrenaline concentrations before and during a $25 \mathrm{ng} / \mathrm{min}$ per $\mathrm{kg}$ ideal body weight adrenaline infusion after $12(0), 36(\square)$ and $72(\bigcirc) \mathrm{h}$ fasting. Values are means for nine subjects, with their standard errors indicated by vertical bars.

Plasma insulin fell from 4.7 (SE $0.9 ; 12 \mathrm{~h}$ ) to $2 \cdot 8$ (SE $0.2 ; 36 \mathrm{~h}$ ) to $2.0(\mathrm{SE} 0.3 ; 72 \mathrm{~h}$ ) $\mathrm{mU} / 1$ $(P<0 \cdot 01$, ANOVA $)$.

Plasma noradrenaline and adrenaline concentrations (Fig. 1)

Basal adrenaline concentrations were 0.28 (SE 0.04), 0.34 (SE 0.05) and 0.44 (SE 0.09) nmol/1 (NS, ANOVA), noradrenaline concentrations were 0.81 (SE 0.07), 0.79 (SE 0.08) and 1.00 (SE $0.12) \mathrm{nmol} / \mathrm{l}$ (NS, ANOVA), and the concentrations of adrenaline in the infusates were 2.74 (SE 0.14), 2.55 (SE 0.13) and 2.77 (SE 0.11) $\mu \mathrm{g} / \mathrm{ml}$ (NS, ANOVA), after 12, 36 and $72 \mathrm{~h}$ respectively. Infusion of adrenaline resulted in mean steady-state plasma adrenaline levels, over the last hour of the infusion, of 2.41 (SE 0.11), 2.32 (SE 0.08) and 2.42 (SE 0.13) nmol/1 respectively (NS, ANOVA). Noradrenaline levels increased significantly after $10 \mathrm{~min}$ of the adrenaline infusion on all visits (time effect, $P<0.01$, ANOVA). The magnitude and duration of this response appeared greater after 36 and $72 \mathrm{~h}$ than after $12 \mathrm{~h}$, but this did not reach statistical significance.

Metabolic rate and respiratory exchange ratio (Fig. 2)

RMR values were 92.6 (SE 4.8), 95.6 (SE 3.6) and 93.4 (SE 5.4) J/min per kg fat-free mass after 12,36 and $72 \mathrm{~h}$ fasting respectively (NS). Since skinfolds, and hence fat-free mass, were only measured after the $12 \mathrm{~h}$ fast, the increases in RMR after 36 and $72 \mathrm{~h}$ fasting are actually somewhat less marked than would actually be the case if fat-free mass had been 

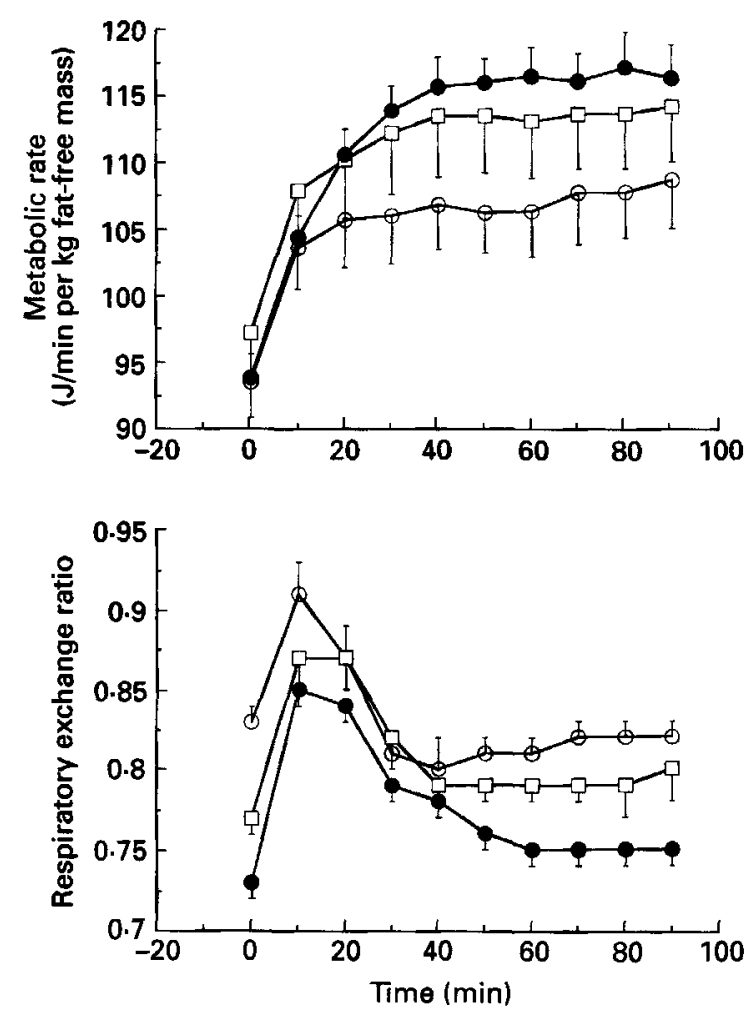

Fig. 2. Metabolic rate and respiratory exchange ratio before and during a $25 \mathrm{ng} / \mathrm{min}$ per $\mathrm{kg}$ ideal body weight adrenaline infusion after $12(\mathrm{O}), 36(\square)$ and $72(O) \mathrm{h}$ fasting. Values are means for nine subjects, with their standard errors indicated by vertical bars.

assessed at $36 \mathrm{~h}$ and $72 \mathrm{~h}$ when most of any weight reduction would be of the fat-free mass. The duration of fasting had a significant effect on the magnitude of the thermogenic response to adrenaline infusion $(P<0.001$, ANOVA). The mean rises over the baseline value during the last $30 \mathrm{~min}$ of the adrenaline infusion were 14.6 (SE 1.7), 16.6 (SE 1.8) and 22.6 (SE 1.6) $\mathrm{J} / \mathrm{min}$ per $\mathrm{kg}$ fat-free mass after 12,36 and $72 \mathrm{~h}$ respectively. There was no significant difference between the 12 and $36 \mathrm{~h}$ values, but the rise at $72 \mathrm{~h}$ was greater than that at $12 \mathrm{~h}(P<0.01$, paired $t$ test $)$, although this did not achieve statistical significance when compared with the $36 \mathrm{~h}$ increase $(P=0 \cdot 07$, paired $t$ test).

RER fell progressively from 0.83 (SE 0.01 ) to 0.77 (SE 0.01 ) to 0.73 (SE 0.01 ). After each period of fasting RER rose initially in response to adrenaline, but then fell back towards the basal value by $60 \mathrm{~min}$ of the infusion.

Heart rate, blood pressure and forearm blood flow (Fig. 3)

Fasting increased resting HR from 62.1 (SE 2.9; $12 \mathrm{~h}$ ) to 67.4 (SE 2.9; $36 \mathrm{~h}$ ) to 68.3 (SE 2.5; $72 \mathrm{~h})$ beats $/ \min (P<0.01$, ANOVA). Both the 36 and $72 \mathrm{~h}$ values were greater than the value at $12 \mathrm{~h}(P<0.05)$, but there was no significant difference between them. In response to the adrenaline infusion HR rose by a similar amount in all cases, the mean rises over resting HR during the last hour of infusion being 17.1 (SE 2.9), 19.2 (SE 2.1) and 20.4 (SE 2.2) beats/min respectively (NS, ANOVA).

There was no effect of fasting on basal systolic blood pressure (SBP). In response to adrenaline SBP rose significantly over the last hour by 5.3 (SE $1.4 ; P<0.01$ ), 4.6 (SE 1.7; 

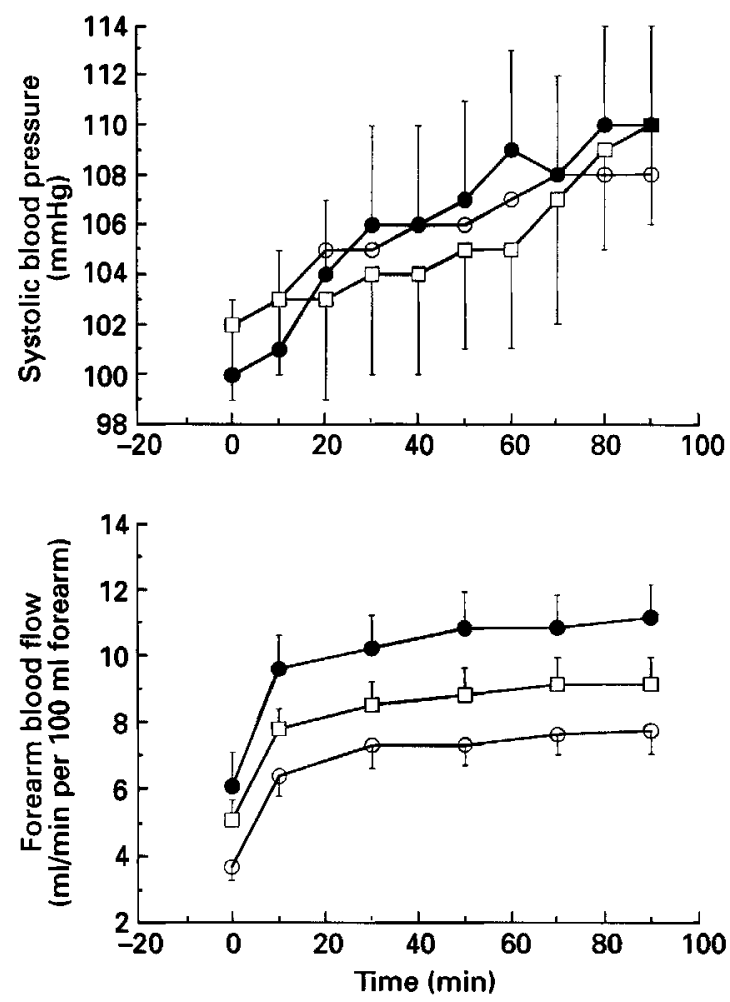

Fig. 3. Systolic blood pressure and forearm blood flow before and during a $25 \mathrm{ng} / \mathrm{min}$ per $\mathrm{kg}$ ideal body weight adrenaline infusion after $12(0), 36(\square)$ and $72(0) \mathrm{h}$ fasting. Values are means for nine subjects, with their standard errors indicated by vertical bars.

$P<0.05$ ) and 7.8 (SE $2.1 ; P<0.01) \mathrm{mmHg}$, after 12,36 and $72 \mathrm{~h}$ respectively, but there was no significant difference in the magnitude of these rises. Basal diastolic blood pressure (DBP) fell from 51.1 (SE $1.9 ; 12 \mathrm{~h}$ ) to 49.9 (SE $1.9 ; 36 \mathrm{~h}$ ) to 46.8 (SE $2 \cdot 1$ ) $\mathrm{mmHg}$ (72 h), but this fall was not statistically significant $(P=0 \cdot 20$, ANOVA). During the last hour of adrenaline infusion DBP fell significantly after $36 \mathrm{~h}$ fasting $(P<0.05)$, but was not significantly changed after 12 and $72 \mathrm{~h}$.

FBF increased from 3.73 (SE 0.43 ) to 5.13 (SE 0.62 ) to 6.12 (SE 0.96 ) $\mathrm{ml} / \mathrm{min}$ per $100 \mathrm{ml}$ forearm after 12,36 and $72 \mathrm{~h}$ of fasting respectively $(P<0.01$, ANOVA). In response to adrenaline FBF rose by 3.81 (SE 0.54), 3.79 (SE 0.73) and 4.66 (SE 0.76) $\mathrm{ml} / \mathrm{min}$ per $100 \mathrm{ml}$ forearm respectively during the last hour of the infusion (NS, ANOVA).

\section{Blood glucose, lactate, glycerol, 3-hydroxybutyrate and plasma non-esterified fatty acids}

\section{(Fig. 4)}

Basal blood glucose concentration fell progressively with duration of fasting from 4.39 (SE 0.07 ) to 3.74 (SE 0.11 ) to 3.16 (SE 0.15$) \mathrm{mmol} / 1(P<0.001$, ANOVA). In response to adrenaline blood glucose concentration rose by 0.97 (SE $0.17 ; 12 \mathrm{~h}), 0.59(\mathrm{SE} 0 \cdot 16 ; 36 \mathrm{~h})$ and 0.58 (SE $0.15 ; 72 \mathrm{~h}) \mathrm{mmol} / 1$ by the end of the infusion $(P<0.01$, ANOVA), the increases at 36 and $72 \mathrm{~h}$ both being smaller than that at $12 \mathrm{~h}(P<0.001$, paired $t$ tests).

Blood lactate levels were unaffected by fasting, being 0.43 (SE 0.03), 0.61 (SE 0.12) and 0.54 (SE 0.03 ) $\mathrm{mmol} / \mathrm{l}$ after 12,36 and $72 \mathrm{~h}$ respectively. There was a significant effect of fasting 

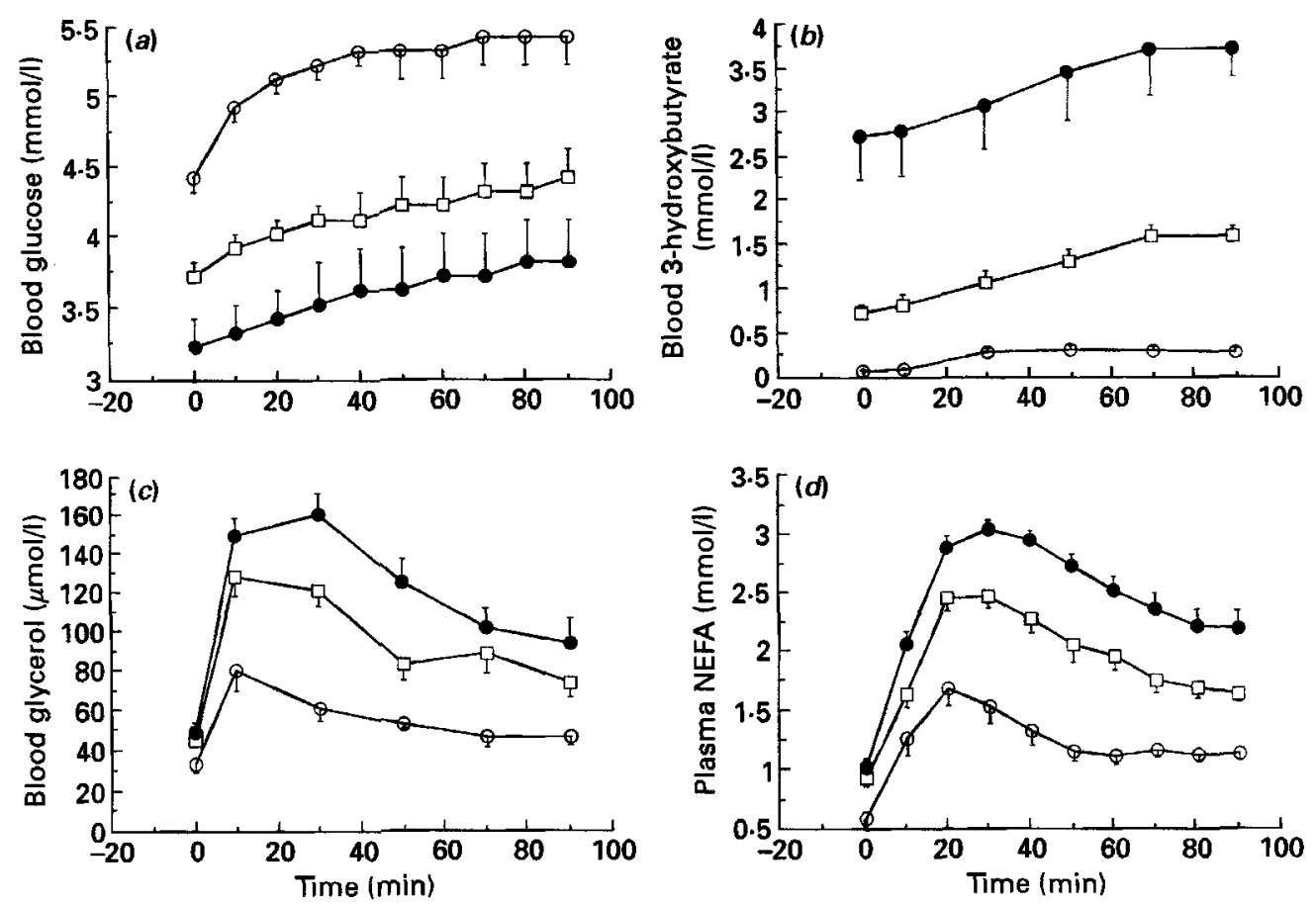

Fig. 4. (a) Blood glucose, (b) blood 3-hydroxybutyrate, (c) blood glycerol and (d) plasma non-esterified fatty acids (NEFA) before and during a $25 \mathrm{ng} / \mathrm{min}$ per $\mathrm{kg}$ ideal body weight adrenaline infusion after $12(\mathrm{O}), 36(\square)$ and 72 (O) $\mathrm{h}$ fasting. Values are means for nine subjects with their standard errors indicated by vertical bars.

on the response to adrenaline $(P<0.05$, ANOVA), the rise in lactate being greater after $36 \mathrm{~h}(P=0.05)$ and $72 \mathrm{~h}(P<0.05)$ than that at $12 \mathrm{~h}$. Over the middle $30 \mathrm{~min}$ of adrenaline infusion the mean increases were 0.38 (SE $0.09 ; 12 \mathrm{~h}$ ), 0.60 (SE $0.12 ; 36 \mathrm{~h}$ ) and 0.78 (SE $0 \cdot 24) \mathrm{mmol} / \mathrm{l}(72 \mathrm{~h})$.

Blood glycerol increased from 34.6 (SE 4.3) to 47.2 (SE 2.5 ) to 50.8 (SE 5.2) $\mu \mathrm{mol} / 1$ with fasting $(P<0.05$, ANOVA), there being no difference between the 36 and $72 \mathrm{~h}$ values, but both being greater than the $12 \mathrm{~h}$ value $(P<0.001$, paired $t$ tests). Duration of fasting affected the glycerol response to adrenaline $(P<0.001$, ANOVA), with a progressive rise in the peak increase in glycerol from 47.7 (SE $6.7 ; 12 \mathrm{~h}$ ) to $82.5(\mathrm{SE} 9 \cdot 1 ; 36 \mathrm{~h}$ ) to 110.9 (SE 10.4$) \mu \mathrm{mol} / 1(72 \mathrm{~h}$ ). The $36 \mathrm{~h}$ response was significantly greater than that at $12 \mathrm{~h}$ ( $P<0.001$, paired $t$ test), and the $72 \mathrm{~h}$ response was greater than that at $36 \mathrm{~h}(P<0.05$, paired $t$ test).

Plasma NEFA concentrations rose during fasting from 0.60 (SE 0.09) to 0.94 (SE 0.07) to $1.03($ SE 0.07$) \mathrm{mmol} / 1(P<0.001$, ANOVA). The proportion of palmitate to total NEFA was unaffected by fasting, being 29 (SE 2), 30 (SE 2) and 27 (SE 2) \% after 12, 36 and $72 \mathrm{~h}$ respectively. There was a significant effect of duration of fast on the magnitude of the NEFA response to adrenaline ( $P<0.001$, ANOVA). The maximum increment in plasma NEFA rose progressively, being 0.89 (SE 0.06) mmol/1 at $12 \mathrm{~h}, 1.25$ (SE 0.09) $\mathrm{mmol} / 1$ at $36 \mathrm{~h}$ $(P<0.01$ v. $12 \mathrm{~h})$ and $1.70(\mathrm{se} 0.07) \mathrm{mmol} / 1$ at $72 \mathrm{~h}(P<0.01$ v. $36 \mathrm{~h})$.

Basal blood 3-hydroxybutyrate levels rose from 0.08 (SE 0.02 ) to 0.74 (SE 0.10 ) to 2.74 (SE $0.49) \mathrm{mmol} / 1$ with fasting. In response to the adrenaline infusion there was a significantly greater rise in 3-hydroxybutyrate after the 36 and $72 \mathrm{~h}$ fasts $(P<0.001$, ANOVA $)$. By the 
Table 1. Plasma $\left[1-{ }^{13} \mathrm{C}\right]$ palmitate atom percent excess $(A P E)$ and plasma palmitate turnover and oxidation before and during adrenaline infusion after 12,36 and $72 \mathrm{~h}$ fasting $\dagger$

(Mean values with their standard errors for nine subjects)

\begin{tabular}{|c|c|c|c|c|c|c|}
\hline & \multicolumn{6}{|c|}{ Duration of fasting (h) } \\
\hline & \multicolumn{2}{|c|}{12} & \multicolumn{2}{|c|}{36} & \multicolumn{2}{|c|}{72} \\
\hline & Mean & SE & Mean & SE & Mean & SE \\
\hline Basal plasma $\left[1{ }^{13} \mathrm{C}\right]$ palmitate APE & $1 \cdot 75$ & 0.24 & $1 \cdot 51 * *$ & $0 \cdot 31$ & $1 \cdot 13^{* *}$ & $0 \cdot 21$ \\
\hline $\begin{array}{l}\text { Basal palmitate turnover ( } \mu \mathrm{mol} / \mathrm{min} \text { per } \mathrm{kg} \\
\text { body wt) }\end{array}$ & 1.48 & 0.22 & $1 \cdot 95^{* *}$ & 0.34 & $2 \cdot 26 * *$ & 0.33 \\
\hline $\begin{array}{l}\text { Basal palmitate oxidation ( } \mu \mathrm{mol} / \mathrm{min} \text { per } \mathrm{kg} \\
\text { body } \mathrm{wt} \text { ) }\end{array}$ & 0.64 & 0.09 & $0 \cdot 85^{*}$ & $0 \cdot 16$ & $0-83^{*}$ & $0 \cdot 11$ \\
\hline Percentage of palmitate turnover oxidized & 44 & 2 & 46 & 5 & 42 & 4 \\
\hline $\begin{array}{l}\text { Plasma }\left[1-{ }^{13} \text { C]palmitate APE at peak turnover in }\right. \\
\text { response to adrenaline }\end{array}$ & 1.09 & 0.09 & 0.91 & $0 \cdot 12$ & $0.84^{*}$ & 0.07 \\
\hline $\begin{array}{l}\text { Peak palmitate turnover in response to } \\
\text { adrenaline }(\mu \mathrm{mol} / \mathrm{min} \text { per } \mathrm{kg} \text { body } \mathrm{wt})\end{array}$ & $2 \cdot 31$ & 0.36 & $2 \cdot 79 * *$ & 0.67 & $2 \cdot 97^{* *}$ & 0.73 \\
\hline $\begin{array}{l}\text { Plasma }\left[1-{ }^{13} \text { C }\right] \text { palmitate APE over last } 30 \mathrm{~min} \text { in } \\
\text { response to adrenaline }\end{array}$ & $1 \cdot 22$ & 0.12 & 1.06 & $0 \cdot 12$ & $1.03^{*}$ & 0.13 \\
\hline $\begin{array}{l}\text { Palmitate turnover over last } 30 \mathrm{~min} \text { of adrenaline } \\
(\mu \mathrm{mol} / \mathrm{min} \text { per } \mathrm{kg} \text { body } \mathrm{wt})\end{array}$ & 1.99 & 0.22 & $2 \cdot 33^{*}$ & 0.35 & $2 \cdot 28^{*}$ & 0.33 \\
\hline $\begin{array}{l}\text { Palmitate oxidation over last } 30 \mathrm{~min} \text { of } \\
\text { adrenaline }(\mu \mathrm{mol} / \mathrm{min} \text { per } \mathrm{kg} \text { body } \mathrm{wt})\end{array}$ & 0.66 & 0.09 & 0.78 & $0 \cdot 11$ & 0.49 & 0.08 \\
\hline $\begin{array}{l}\text { Percentage of palmitate turnover oxidized over } \\
\text { last } 30 \mathrm{~min}\end{array}$ & 34 & 3 & 36 & 4 & $25^{*}$ & 4 \\
\hline
\end{tabular}

Mean values were significantly different from the corresponding $12 \mathrm{~h}$ value: ${ }^{*} P<0 \cdot 05,{ }^{*} P<0.01$ (paired $t$ test).

$\dagger$ For details of procedures, see pp. $478-480$.

end of the adrenaline infusion 3-hydroxybutyrate levels had risen by 0.22 (SE 0.05) $\mathrm{mmol} / 1$ at $12 \mathrm{~h}, 0.87(\mathrm{SE} 0.06) \mathrm{mmol} / 1$ at $36 \mathrm{~h}(P<0.001$ v. $12 \mathrm{~h}$, paired $t$ test) and 1.00 (SE $0.12) \mathrm{mmol} / \mathrm{l}$ at $72 \mathrm{~h}$ (not significantly different from the rise at $36 \mathrm{~h}$ ).

\section{Blood urea and urinary nitrogen excretion}

Mean blood urea concentrations at the start of each study were 4.2 (SE 0.1), 4.4 (SE 0.3) and 5.0 (SE 0.5) mmol/l after 12, 36 and $72 \mathrm{~h}$ respectively (NS, ANOVA). At the end of each study the values were 4.0 (SE 0.2), 4.6 (SE 0.3) and 4.7 (SE 0.4) mmol/1 respectively. There were no significant changes in blood urea concentrations at any time.

The basal urinary $\mathrm{N}$ excretion rates were 7.0 (SE 0.9$) \mathrm{mg} / \mathrm{min}$ after $12 \mathrm{~h}, 6.5$ (SE 1.4) $\mathrm{mg} / \mathrm{min}$ after $36 \mathrm{~h}$ and $6.8(\mathrm{SE} 0.9) \mathrm{mg} / \mathrm{min}$ after $72 \mathrm{~h}$. Over the period of the adrenaline infusion the mean urinary $\mathrm{N}$ excretion rates were 8.6 (SE 1.2), 11.0 (SE 1.6) and 8.0 (SE 1.0) $\mathrm{mg} / \mathrm{min}$ respectively (NS, ANOVA). The rise in urinary $\mathrm{N}$ excretion in response to adrenaline did not reach significance at any time.

Palmitate and fatty acid turnover and oxidation (Fig. 5 and Table 1)

Basal plasma palmitate turnover rose with fasting $(P<0.001$, ANOVA) (total NEFA turnover values, calculated from the plasma palmitate:plasma NEFA concentration ratio, were 5.23 (SE 0.87), 6.50 (SE 1.04) and 8.37 (SE 1.14) $\mu \mathrm{mol} / \mathrm{min}$ per $\mathrm{kg}$ body weight). The values obtained for expired-air $\mathrm{CO}_{2}$ enrichment, which were used in the calculation of palmitate oxidation rates, are presented in Fig. 5. Basal plasma palmitate oxidation rates 


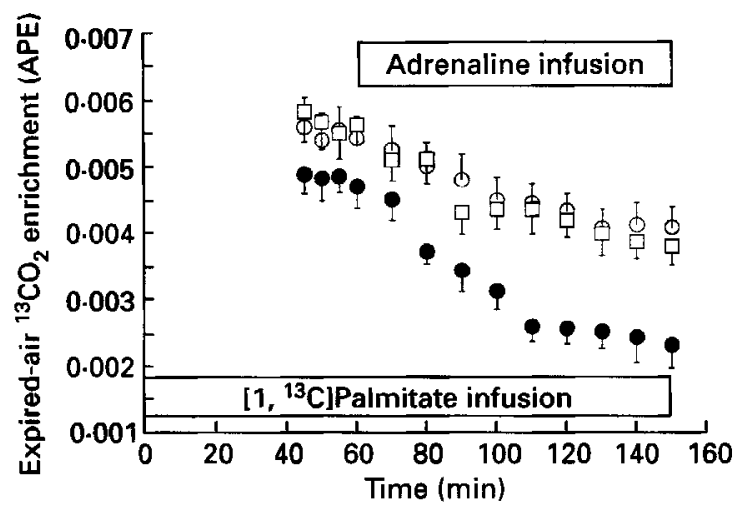

Fig. 5. Expired air ${ }^{13} \mathrm{CO}_{2}$ enrichment (atom percent excess, APE) before and during a $25 \mathrm{ng} / \mathrm{min}$ per $\mathrm{kg}$ ideal body weight adrenaline infusion after $12(\mathrm{O}), 36(\square)$ and $72(\mathrm{O}) \mathrm{h}$ fasting. Values are means for nine subjects, with their standard errors indicated by vertical bars.

also increased with fasting $(P<0 \cdot 01$, ANOVA) (equivalent to plasma NEFA oxidation rates of 2.24 (SE 0.37), 2.95 (SE 0.55) and 3.21 (SE 0.47) $\mu \mathrm{mol} / \mathrm{min}$ per $\mathrm{kg}$ body weight). The percentage of the palmitate turnover oxidized was not affected by fasting. Total lipid oxidation (calculated from indirect calorimetry and expressed as mol NEFA for comparison with plasma oxidation rates) rose from 3.19 (SE 0.41) to 4.77 (SE 0.28) to 5.33 (SE $0 \cdot 15) \mu \mathrm{mol} / \mathrm{min}$ per $\mathrm{kg}$ body weight ( $P<0.001$, ANOVA).

In response to the infusion of adrenaline, palmitate turnover rose after all periods of fasting (adrenaline effect, $P<0.001$, ANOVA), with no significant difference in the patterns of the responses. Palmitate oxidation rates were only calculated during the last 50 min of the adrenaline infusion, because the increase in total $\dot{\mathrm{VCO}}_{2}$ seen during the first 40 min of the infusion (illustrated by the rise in RER over this period) reflects a change in ventilatory pattern rather than an alteration in substrate utilization. Adrenaline infusion had no significant effect on palmitate oxidation rates after 12 and $36 \mathrm{~h}$ fasting, but reduced palmitate oxidation rates after the $72 \mathrm{~h}$ fast $(P<0.05$, ANOVA). There was, however, no significant difference between these responses. The percentage palmitate turnover oxidized fell in response to adrenaline infusion (adrenaline effect, $P<0.001$, ANOVA). This fall only reached statistical significance after the $72 \mathrm{~h}$ fast $(P<0.05$, ANOVA). Total lipid oxidation rates during the last $30 \mathrm{~min}$ adrenaline infusion were 2.60 (SE 0.27), 3.08 (SE 0.34) and 4.37 (SE 0.26) $\mu \mathrm{mol} / \mathrm{min}$ per $\mathrm{kg}$ body weight $(P<0.001$, ANOVA).

\section{DISCUSSION}

The present study combines metabolic and cardiovascular measurements to give a more integrated view of early starvation than previous work. Starvation caused an increase in the thermogenic and metabolic responses to adrenaline, but no significant change in cardiovascular sensitivity. The thermogenic response to adrenaline increased from $14.6 \mathrm{~J} / \mathrm{min}$ per $\mathrm{kg}$ fat-free mass after the overnight fast, to $22.6 \mathrm{~J} / \mathrm{min}$ per $\mathrm{kg}$ fat-free mass after $72 \mathrm{~h}$ fasting. A similar increase in thermogenic sensitivity has been demonstrated after a $48 \mathrm{~h}$ fast (Mansell et al. 1990). Since equivalent plasma concentrations of adrenaline and noradrenaline were achieved during the adrenaline infusion, after all three periods of fasting, the enhanced responsiveness must be due to an increase in adrenoceptor sensitivity. This enhanced responsiveness contrasts with the finding that $7 \mathrm{~d}$ underfeeding has no effect on the thermogenic response to adrenaline (Mansell \& Macdonald, 1989), and that chronic 
undernutrition may actually reduce this response (Kurpad et al. 1989). A possible explanation for this effect of fasting is the lower concentration of insulin. Insulin is known to have powerful antilipolytic effects and may also have inhibitory effects on adrenalinestimulated thermogenesis (Piolino et al. 1990). However, stimulation of thermogenesis by adrenaline in the non-fasted state has been shown to be independent of changes in insulin and glucagon (Staten $e t$ al. 1989). The effects of the adrenaline infusion on plasma insulin levels were not measured in the present study, but previous work has shown similar increases in insulin after 12 and $48 \mathrm{~h}$ fasting (Mansell et al. 1990).

There were marked cardiovascular changes in response to fasting, with both basal HR and FBF increasing. This limb vasodilation may be related to a vasoactive effect of ketone bodies (Webber et al. 1994) whose concentrations increased 30 -fold after $72 \mathrm{~h}$ fasting. However, fasting did not significantly potentiate the responses of these variables to infused adrenaline. There was a tendency for the HR response to increase with fasting (HR increment $17.1 \mathrm{beats} / \mathrm{min}$ at $12 \mathrm{~h}$ and 20.4 beats $/ \mathrm{min}$ at $72 \mathrm{~h}$ ). Previous studies have shown such an increase both after a $48 \mathrm{~h}$ fast in healthy subjects (Mansell et al. 1990) and in chronically undernourished labourers (Jayarajan \& Shetty, 1987).

The infusion of adrenaline caused an increase in blood glucose level which was greatest in the overnight fasted state. This increase results from the stimulation of both glycogenolysis and gluconeogenesis and from an inhibition of splanchnic and peripheral glucose uptake (Sacca et al. 1983). Glycogenolysis contributes the major part of this response after a $12 \mathrm{~h}$ fast, but by $24 \mathrm{~h}$ onwards hepatic glycogen stores are almost completely depleted (Nilsson \& Hultman, 1973) and thus the response is attenuated. Despite this attenuation in glucose production the rise in blood lactate in response to adrenaline was greater after both 36 and $72 \mathrm{~h}$ fasting than after $12 \mathrm{~h}$. A possible reason for this may be increased flux through the glycolytic pathway relative to the oxidative pathway in muscle after fasting, because of the inhibition of pyruvate dehydrogenase which occurs during fasting. In addition the prevailing hyperketonaemia may impair hepatic uptake of the lactate (Metcalfe et al. 1986), although greater hepatic lactate uptake might be expected during fasting in view of its role as a gluconeogenic substrate.

The most marked effects of fasting were on the magnitude of the increase in blood glycerol and plasma NEFA concentrations resulting from the infusion of adrenaline. In response to adrenaline, blood glycerol concentration rose by $48 \mu \mathrm{mol} / \mathrm{l}$ in the $12 \mathrm{~h}$ fasted state and by $111 \mu \mathrm{mol} / 1$ after the $72 \mathrm{~h}$ fast. The corresponding values for the rise in plasma NEFA concentration were 0.89 and $1.70 \mathrm{mmol} / 1$ respectively. Basal turnover rates of plasma palmitate rose from 1.48 to $2.26 \mu \mathrm{mol} / \mathrm{min}$ per kg body weight after 12 and $72 \mathrm{~h}$ fasting respectively. These values compare with those reported recently by Klein et al. (1993) of 1.63 and $3.26 \mu \mathrm{mol} / \mathrm{min}$ per $\mathrm{kg}$ body weight after identical periods of fasting. Thus, the effect of fasting on basal lipolysis was somewhat less marked in the present study. In addition, the increase in plasma fatty acid turnover in response to adrenaline was not greater after the $72 \mathrm{~h}$ fast than after the overnight fast. This contrasts with earlier studies where fasting caused a potentiation of this response (Jensen et al. 1987; Wolfe et al. 1987). The reasons for this disparity are not clear, but may relate to the different plasma concentrations of adrenaline achieved in the studies $(2.4 \mathrm{nmol} / 1$ in the present study $v$. $1.5 \mathrm{nmol} / 1$ in the study of Jensen $e t$ al. 1987). It may be that the higher concentrations of adrenaline seen in the present study mask the potentiating effect of fasting, perhaps via greater stimulation of insulin secretion.

A potentiating effect of fasting on the lipolytic response to adrenaline has been seen in several studies (Mansell et al. 1990; Wolfe et al. 1987). Although the lower insulin levels seen during fasting may remove an antilipolytic influence, even when insulin levels are restored to those seen after a $12 \mathrm{~h}$ fast there is still a potentiation of the lipolytic response 
(Jensen et al. 1987). Similarly, the decline in blood glucose does not fully account for the enhanced lipolytic sensitivity (Klein et al. 1990). Increased adipocyte sensitivity to adrenergic stimulation may therefore be important in the mobilization of fat stores during fasting.

In assessing lipolysis, plasma glycerol and NEFA concentrations provide only an indirect indication of this process, since their plasma levels reflect both utilization and production rates. Turnover rates of glycerol, in theory, give the most accurate assessment of lipolytic rates. NEFA turnover, on the other hand, may not truly reflect absolute lipolytic rates since fatty acids can be re-esterified back to triacylglycerols within adipocytes, whereas glycerol cannot be since the enzyme glycerol kinase $(E C 2.7 .1 .30)$ is absent from adipocytes (Vaughan, 1961). Furthermore, lipolysis of triacylglycerols stored within skeletal muscle may yield NEFA which are oxidized within the muscle and thus do not appear in plasma (Dagenais et al. 1976). In the current study there was a much greater increment in plasma NEFA concentrations than there was in plasma NEFA turnover in response to adrenaline after a $72 \mathrm{~h}$ fast. It seems likely that this greater increment in plasma concentration reflects both a relative fall in utilization of NEFA (the percentage of palmitate turnover oxidized fell during adrenaline infusion) and an increase in oxidation of intramuscular fatty acids.

In the current study fasting increased both plasma fatty acid turnover and oxidation in the baseline state to a similar extent. Thus the proportion of the turnover which was oxidized remained constant at about $45 \%$. Similarly, plasma fatty acid oxidation comprised a roughly constant $65 \%$ of total lipid oxidation in the baseline state after the different periods of fasting. In response to adrenaline the proportion of the turnover which was oxidized fell, with this fall being most marked after the $72 \mathrm{~h}$ fast. Total lipid oxidation also fell somewhat, but the fall in plasma fatty acid oxidation was greater, suggesting that intratissue lipid oxidation was favoured over plasma fatty acid oxidation.

The calculations of plasma fatty acid oxidation depend on a number of assumptions. In most studies of plasma fatty acid oxidation a constant correction factor is used to allow for the fact that not all the ${ }^{13} \mathrm{CO}_{2}$ produced at the cellular level is excreted in the breath. The value 0.76 was used in the present study, but it is not known whether either starvation or infusion of adrenaline changes the proportion of ${ }^{13} \mathrm{CO}_{2}$ production excreted. In addition, both as starvation progresses and in response to adrenaline, more palmitate oxidation will occur via ketone bodies. The ${ }^{13} \mathrm{C}$ enrichment of ketone bodies may not have reached steady state during the current studies, which would tend to have the greatest effect at the end of the $72 \mathrm{~h}$ study in apparently reducing the percentage of palmitate turnover oxidized. Heiling et al. (1991) also observed that isotopic estimates of fatty acid oxidation were lower than indirect calorimetry measurements of total lipid oxidation in the basal state. However, unlike the present study, they found that the isotopic estimates of fatty acid oxidation exceeded total lipid oxidation when lipolysis was increased due to acute hypoinsulinaemia. This appears to result from a delay between exit of the fatty acid tracer from the plasma and the appearance of the tracer as ${ }^{13} \mathrm{CO}_{2}$. Longer durations of adrenaline infusion may therefore be necessary to overcome all the above potential sources of error and hence give more accurate results.

The present study confirms the findings of others that fasting potentiates the thermogenic response to adrenaline. The exact site and mechanism of catecholamine-induced thermogenesis remains uncertain, but skeletal muscle (Lundholm \& Svedmyr, 1965), the splanchnic bed (Bearn et al. 1951) and adipose tissue (Simonsen et al. 1992) may be important. The fact that adrenaline appears to favour oxidation of intratissue fatty acids over those from the plasma fatty acid pool may be responsible for the enhanced skeletal muscle thermogenesis. There was no convincing evidence in the present study that fasting enhances the cardiovascular responses to adrenaline. 
The authors would like to thank Linda Ashworth for the measurements of intermediary metabolites and David Forster for catecholamine analyses. They are also grateful to The Wellcome Trust and the Agricultural and Food Research Council for their financial support.

\section{REFERENCES}

Allsop, J. R., Wolfe, R. R. \& Burke, J. F. (1978). Tracer priming the bicarbonate pool. American Journal of Physiology 45, 137-139.

Bearn, A. G., Billing, B. \& Sherlock, S. (1951). The effect of adrenaline and noradrenaline on hepatic blood flow and splanchnic carbohydrate metabolism in man. Journal of Physiology 115, 430-441.

Dagenais, G. R., Tancredi, R. D. \& Zierler, K. L. (1976). Free fatty acid oxidation by forearm muscle at rest, and evidence for an intramuscular lipid pool in the human forearm. Journal of Clinical Investigation 58, 421-431.

Durnin, J. V. G. A. \& Womersley, J. (1974). Body fat assessed from total body density and its estimation from skinfold thickness: measurements on 481 men and women aged from 16 to 72 years. British Journal of Nutrition 32, 77-97.

Fellows, I. W. \& Macdonald, I. A. (1985). An automated method for the measurement of oxygen consumption and carbon dioxide excretion in man. Clinical Physics and Physiological Measurement 6, 349-355.

Hachey, D. L., Patterson, B. W., Reeds, P. J. \& Elsas, L. J. (1991). Isotope determination of organic keto acid pentafluorobenzyl esters in biological fluids by negative chemical ionization gas chromatography/mass spectrometry. Analytical Chemistry 63, 919-923.

Heiling, V. J., Miles, J. M. \& Jensen, M. D. (1991). How valid are isotopic measurements of fatty acid oxidation? American Journal of Physiology 261, E572-E577.

Jayarajan, M. P. \& Shetty, P. S. (1987). Cardiovascular $\beta$-adrenoceptor sensitivity of undernourished subjects. British Journal of Nutrition 58, 5-11.

Jensen, M. D., Haymond, M. W., Gerich, J. E., Cryer, P. E. \& Miles, J. M. (1987). Lipolysis during fasting: decreased suppression by insulin and increased stimulation by epinephrine. Journal of Clinical Investigation 79 , 207-213.

Jensen, M. D., Heiling, V. \& Miles, J. M. (1990). Measurement of non-steady state free fatty acid turnover. American Journal of Physiology 258, E103-E108.

Jequier, E., Acheson, K. \& Schutz, Y. (1987). Assessment of energy expenditure and fuel utilization in man. Annual Review of Nutrition 7, 187-208.

Klein, S., Holland, O. B. \& Wolfe, R. R. (1990). Importance of blood glucose concentration in regulating lipolysis during fasting in humans. American Journal of Physiology 258, E32-E39.

Klein, S., Peters, E. J., Holland, O. B. \& Wolfe, R. R. (1989). Effect of short-and long-term $\beta$-adrenergic blockade on lipolysis during fasting in humans. American Journal of Physiology 257, E65-E73.

Klein, S., Sakurai, Y., Romijn, J. A. \& Carroll, R. M. (1993). Progressive alterations in lipid and glucose metabolism during short-term fasting in young adult men. American Journal of Physiology 265, E801-E806.

Knox, D. P. \& Jones, D. G. (1984). Automated enzymatic determination of plasma free fatty acids by centrifugal analysis. Journal of Automatic Chemistry 6, 152-154.

Kurpad, A. V., Kulkarni, R. N., Sheela, M. L. \& Shetty, P. S. (1989). Thermogenic responses to graded doses of noradrenaline in undernourished Indian male subjects. British Journal of Nutrition 61, 201-208.

Landsberg, L. \& Young, J. B. (1978). Fasting, feeding and regulation of the sympathetic nervous system. New England Journal of Medicine 298, 1295-1301.

Livesey, G. \& Elia, M. (1988). Estimation of energy expenditure, net carbohydrate utilization, and net fat oxidation and synthesis by indirect calorimetry: evaluation of errors with special reference to the detailed composition of fuels. American Journal of Clinical Nutrition 47, 608-628.

Lloyd, B., Burrin, J., Smythe, P. \& Alberti, K. G. M. M. (1978). Enzymatic fluorometric continuous-flow assays for blood glucose, lactate, pyruvate, alanine, glycerol and 3-hydroxybutyrate. Clinical Chemistry 34, 1724-1729.

Lundholm, L. \& Svedmyr, N. (1965). Influence of adrenaline on blood flow and metabolism in the human forearm. Acta Physiologica Scandinavica 65, 344-351.

Macdonald, I. A. \& Lake, D. M. (1985). An improved technique for extracting catecholamines from body fluids. Journal of Neuroscience Methods 13, 239-248.

McGuire, E. A. H., Helderman, J. H., Tobin, J. D., Andres, R. \& Berman, M. (1976). Effects of arterial versus venous sampling on analysis of glucose kinetics in man. Journal of Applied Physiology 41, 565-573.

Mansell, P. I., Fellows, I. W. \& Macdonald, I. A. (1990), 48 h starvation enhances the thermogenic response to infused adrenaline. American Journal of Physiology 258, R87-R93.

Mansell, P. I. \& Macdonald, I. A. (1989). Underfeeding and the physiological responses to infused epinephrine in lean women. American Journal of Physiology 256, R583-R589.

Metcalfe, H. K., Monson, J. P., Welch, S. G. \& Cohen, R. D. (1986). Inhibition of lactate removal by ketone bodies in rat liver: evidence for a quantitatively important role of the plasma membrane lactate transporter in lactate metabolism. Journal of Clinical Investigation 78, 743-747.

Nilsson, L. H. \& Hultman, E. (1973). Liver glycogen in man - the effect of total starvation or a carbohydrate-poor 
diet followed by carbohydrate refeeding. Scandinavian Journal of Clinical and Laboratory Investigation 32, 325-330.

O’Dea, K., Esler, M., Leonard, P., Stockigt, J. R. \& Nestel, P. (1982). Noradrenaline turnover during under- and over-eating in normal weight subjects. Metabolism 31, 896-899.

Piolino, V., Acheson, K. J., Muller, M. J., Jeanpretre, N., Burger, A. G. \& Jequier, E. (1990). Thermogenic effect of thyroid hormones: interactions with epinephrine and insulin. American Journal of Physiology 259, E305-E311.

Sacca, L., Vigorito, C., Cicala, M., Corso, G. \& Sherwin, R. S. (1983). Role of gluconeogenesis in epinephrinestimulated hepatic glucose production in humans. American Journal of Physiology 245, E294-E302.

Simonsen, L., Bulow, J., Madsen, J. \& Christensen, N. J. (1992). Thermogenic response to epinephrine in the forearm and abdominal subcutaneous adipose tissue. American Journal of Physiology 263, E850-E855.

Staten, M. A., Matthews, D. E., Cryer, P. E. \& Bier, D. M. (1989). Epinephrine's effect on metabolic rate is independent of changes in plasma insulin or glucagon. American Journal of Physiology 257, E185-E192.

Vaughan, M. (1961). The metabolism of adipose tissue in vitro. Journal of Lipid Research 2, 293-316.

Webb, P. (1986). 24-hour energy expenditure and the menstrual cycle. American Journal of Clinical Nutrition 44, $614-619$.

Webber, J. \& Macdonald, I. A. (1994). The cardiovascular, metabolic and hormonal changes accompanying acute starvation in men and women. British Journal of Nutrition 71, 437-447.

Webber, J., Simpson, E., Parkin, H. \& Macdonald, I. A. (1994). Metabolic effects of acute hyperketonaemia in man before and during an hyperinsulinaemic euglycaemic clamp. Clinical Science 86, 677-687.

Weir, J. B. de V. (1949). New methods of calculating metabolic rate with special reference to protein metabolism. Journal of Physiology (London) 109, 1-9.

Wenham, D., Pacy, P. J., Halliday, D., Price, G. M. \& Millward, D. J. (1991). Bicarbonate recovery: feeding versus time. Proceedings of the Nutrition Society 50, 47A.

Whitney, R. J. (1953). The measurement of volume changes in human limbs. Journal of Physiology (London) 121, $1-27$.

Wolfe, R. R., Evans, J. E., Mullany, C. J. \& Burke, J. F. (1980). Measurement of plasma free fatty acid turnover and oxidation using $\left[1^{-13} \mathrm{C}\right]$ almitic acid. Biomedical Mass Spectrometry 7, 168-171.

Wolfe, R. R., Peters, E. J., Klein, S., Holland, O. B., Rosenblatt, J. \& Gary, H. Jr (1987). Effect of short-term fasting on lipolytic responsiveness in normal and obese human subjects. American Journal of Physiology 252, E189-E196. 